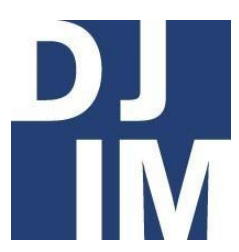

Volume 15

Spring

2019

djim.management.dal.ca |

\title{
No Filter: Social Media in Public-sector Hiring
}

Siobhan Quigg

School of Public Administration, Dalhousie University

\begin{abstract}
This essay analyzes how SM is used in hiring processes through a review of research in the private sector and the relevant policy in the public sector. This analysis presents three key findings: 1 ) there is a lack of policy related to SM screening in the public sector, 2) there is a lack of research on the use of SM in public sector hiring processes, and 3) there are potential areas of conflict between public sector values and the use of SM in hiring processes. Based on these findings, this essay advocates for further research and the development of a federal SM screening policy.
\end{abstract}

Social media (SM) refers to online platforms that enable users to create and share content, such as Facebook (Kaplan and Haenlin, 2010). Although, SM hardly needs defining as it has quickly become commonplace with billions of users (Gruzd et al., 2018, p.3). Hiring staff in the public and private sector alike are not immune to this epidemic, but how does SM change how hiring assessments occur? This essay argues that using SM to screen potential public servants poses a risk to foundational public-sector values such as merit and transparency. However, this essay also proposes that with further research and the development of a federal policy, SM screening may be harnessed to serve, rather than harm, these values. To support this argument, I will first examine the frequency and the manner that SM screening is used by private-sector employers during hiring decisions. Based on private-sector trends, public expectations, and anecdotal evidence, I will argue that the public sector is likely engaged in SM screening processes. This 
essay then offers a brief scan of relevant Canadian policy to expose the lack of pertinent regulation. This is followed by an overview of relevant public-sector values and the risks that SM screening poses to these values. This essay concludes with an assessment of the utility of SM screening against the risks and recommends future research to support a federal SM screening policy.

\section{Social Media in Private Sector Hiring}

Globally, there are billions of people engaged on SM (Gruzd et al., 2018, p.3). Unsurprisingly, the private sector has embraced this emerging reality in order to modernize their talent and recruitment practices. From 2006 to 2016, the number of employers that use SM to screen candidates increased by $500 \%$ (CareerBuilder, 2016). Screening is a term applied to the practice of assessing the skills, experience, and other traits of a given job applicant to inform hiring decisions (Public Safety Canada, 2012, p.7). In an American study conducted in 2017, 70\% of private-sector employers disclosed that they screen candidates on SM before hiring (Salm, 2017). Further, the U.S. Equal Employment Opportunity Commission reported that approximately $75 \%$ of recruiters are required by their employers to investigate all applicants online (Roth et al., 2016, p. 270), and almost a third of employers have staff dedicated exclusively to SM screening (Salm, 2017).
It is clear that SM has permeated all aspects of society and that private-sector recruitment has adapted accordingly, but what attracts employers to SM as a screening device in particular? CareerBuilder Chief Human Resources Officer, Rosemary Haefner, states that "tools such as Facebook and Twitter enable employers to get a glimpse of who candidates are outside the confines of a resume or cover letter" (CareerBuilder, 2016). Meanwhile, independent recruitment specialist Jolene Risch views a candidate's SM presence as an "online resume" stating that "who [the candidate is] twenty-four hours a day is important to the company" (CBSDFW, Nov. 2016). SM offers employers a new and unique opportunity to assess aspects of a candidate beyond the structured and reserved setting of interviews and other traditional screening practices. Information gained through SM screening has the potential to inform a more holistic and candid assessment of the applicant in order to gauge their job suitability and organizational fit. Given the widespread usage of SM screening in the private sector, it is apparent that the majority of employers see the value in SM screening. Many statistics and examples illustrate the ways that SM can inform hiring decisions.

There are a number of studies that demonstrate that SM influences employers' perceptions of potential candidates (Bohnert and Ross, 2010; CareerBuilder, 2016; Jobvite, 2015; Salm, 2017). A Jobvite 
study (2015) found that 55\% of employers reconsidered their hiring decisions based on SM screening. An infamous example of such an occurrence began with a tweet by Connor Riley. Riley, an information management and systems graduate student at the University of California, tweeted: "Cisco just offered me a job! Now I have to weigh the utility of a fatty paycheck against the daily commute to San Jose and hating the work" (as cited in Popkin 2009). This tweet prompted Cisco to publicly contact Riley stating: "Who is the hiring manager. I'm sure they would love to know you will hate the work. We at Cisco are versed in the web" (as cited in Popkin 2009). Unsurprisingly, it has been widely reported that Cisco rescinded Riley's job offer, although Riley denies these allegations, claiming that she declined the position (Popkin 2009; Comstock 2011). Riley's story is one public example of a process that, according to surveys completed by private-sector employers, frequently occurs behind the scenes.

Over half the time that employers reconsider a hiring decision based on SM screening, the information they found during SM screening hurts the applicant (Salm, 2017). However, 44\% of employers have discovered content through SM screening that led them to hire the candidate in question (Salm, 2017). Of the employers that reported SM screening, 92\% reviewed LinkedIn, 66\% reviewed Facebook and 52\% review Twitter (Jobvite, 2015). SM content that causes employers to decide not to hire a candidate includes: discriminatory comments, criminal behaviour, negative comments about previous employers or co-workers, and information that conflicts with stated qualifications (Salm, 2017). While deciding not to hire a candidate because of crime, slander, or false qualifications is rather uncontroversial, employers also cite many more innocuous features of SM that have prompted them not to hire a candidate. For example, drinking or drug consumption, unprofessional screen names, grammatical errors, and posting too frequently have been cited frequently as reasons why an employer decides not to hire an applicant (Salm, 2017). While posting too frequently and oversharing on SM is seen as negative by employers, eliminating all online presence also generates a negative impression.

$57 \%$ of employers are less likely to pursue a candidate that has no SM content (Salm, 2017). Risch asserts that being unable to find an applicant is a red flag for many employers, stating that "if I can't find someone at all, I'm wondering, [...] is this person who they really are" (CBSDFW, Nov. 2016). Alternatively, there are many aspects of a candidate's SM that have directly led to the hiring of the candidate. Of these aspects, employers commonly reported acquiring a better understanding of the candidate's personality to determine organizational fit. Other aspects that have led to a positive outcome for candidates include: SM content that demonstrates a 
professional image, well-roundedness, creativity, communication skills, and awards and achievements (CareerBuilder, 2014). To a lesser degree (less than $24 \%$ of the time), employers who decided to hire a candidate based on SM content cited interaction with the organization's SM accounts and the candidate's number of followers or subscribers as the motivation for the hire (CareerBuilder, 2014).

\section{Social Media in Public-Sector Hiring}

While the use of SM screening in government hiring is significantly less overt, formalized and studied than it is in the private sector, it is reasonable to assume that many public employers are viewing candidates' SM during hiring processes. Unfortunately, there is a significant lack of research on the use of SM in public-sector hiring, which creates a gap in the research in this paper. However, during informal and incidental discussions, over half a dozen Canadian public servants at various governmental levels and departments disclosed that they view candidates' SM during the hiring process. Moreover, the general expectation among citizens that government employers will check a job applicant's SM strongly supports the hypothesis that SM screening has pervaded the public sector. For instance, this expectation is evident in the comments section of a CBC article about government employers checking Facebook before hiring. Stephen White comments: "If you put it out there, you are foolish if you expect privacy. A potential employer will check it out. He 4 would be wrong not to do so" (CBC News, Jan 19, 2018). Furthermore, at Dalhousie University's School of Public Administration, Master of Public Administration students who intend to apply to government positions are advised by the school to polish and professionalize their SM accounts. This advice, in addition to White's comment, reveals an unspoken understanding that public-sector employers will likely review a job applicant's SM.

Although there is evidence to suggest that public-sector employers are reviewing SM during hiring, there is no federal policy in Canada that addresses this practice. The private sector is generally very open and procedural about SM screening practices. For instance, many job applicants are asked directly to provide SM access information to prospective employers (Suen, 2018, p. 396). Three in ten employers have staff designated specifically and exclusively to SM screening (Salm, 2017). There are even companies like Signet that specialize in offering superior SM checks to other firms (Messersmith 2016). In contrast, my review of Canadian legislation and policy reveals that SM screening is a neglected area in public-sector regulation.

The Public Service Commission of Canada (PSC) is responsible for overseeing public service hiring processes in accordance with the Public Service Employment Act (2003). Within the PSC framework, deputy heads have the flexibility to customize staffing programs and processes to meet

Social Media in Hiring 
organizational needs (Public Service Commission, 2011, s.4.10). The PSC has developed a number of guides and policies to standardize the assessment of job applicants including: the Public Service Staffing Guide (2018), a Structured Reference Check User Guide (2015), and Best Practices for Unsupervised Testing (2015). However, none of these documents explicitly prohibits or directs the use of SM in applicant assessments and given the unique nature of SM, these policies cannot adequately govern SM screening. In short, there is a blatant lack of standardized federal oversight on this matter. That said, there is some information on regulations that indirectly relates to the use of SM screening.

The Newfoundland and Labrador Access to Information and Protection of Privacy Act (2015) requires that personal information collected by a public body is done with the consent of the individual in question or with authorization from the commissioner (s.62). However, the collection of personal information does not always take place during screening and merely viewing information can sway hiring decisions. Despite the mass of federal policies around public-sector hiring, my review has revealed that there is no formal, direct, and government-wide instruction on the use of SM during screening. At most, my review has shown there is informal and inconsistent advice against SM viewing from individual human resource departments across the public service. For instance, Donovan Molloy, Information and Privacy Commissioner of Newfoundland and Labrador, publicly stated: "I don't think public bodies in Newfoundland and Labrador should be checking the social media accounts of candidates" (CBC News Jan 19, 2018). However, Molloy's statement is uncodified and was passively expressed as an opinion rather than instruction. To assess the implications of government SM screening in the absence of regulating policy, it is critical to first consider the foundational values and established standards of public-sector hiring.

\section{Values in Hiring}

The Public Service Employment Act (2003) clearly outlines the value-based standards that are foundational to the Canadian public sector. The Act emphasizes merit and non-partisanship as foundational values which must be independently safeguarded to maintain the quality of the public service. The Act also underscores the importance of striving "for excellence, that is representative of Canada's diversity and that is able to serve the public with integrity" (preamble). Moreover, the Act articulates the Government of Canada's commitment to a public service "that is characterized by fair, transparent employment practices" (preamble). In order to examine the role of SM in public-sector hiring, it is necessary to explore the interconnected meanings of merit, transparency, and excellence. 
Merit

In 1918, the Canadian public service adopted the merit principle to lend structure and fairness to the hiring process and eliminate issues related to political patronage (Lindequist, 2006, p.25). The merit principle is the idea that all citizens possess reasonable opportunity to be considered for public service employment and that selections will be assessed based solely on the candidate's fitness to do the job (Kernaghan, 2011, p.3). The adoption of the merit principle was propelled by the idea that the public service requires "competence, discipline, skill and knowledge appropriate for specific positions" (Lindequist, 2016, p. 6). Currently, the merit principle is intended as an aid that guides hiring processes while remaining adaptable to changing circumstances (Kernaghan 2011, p.3). It requires that hiring is conducted in a way that maintains fairness, transparency, access and representativeness (Kernaghan, 2011, p.6). This means that appointment decisions "must be, and must be seen to be, made objectively and free of political influence or personal favouritism" (Public Service Commission, 2011, s.4.6). Meritbased hiring not only supports quality hiring decisions to maintain a strong public service, but it also promotes employee engagement (Kernaghan, 2011).

\section{Transparency}

Transparency refers to a spirit of openness and honesty. It ensures that the public service maintains respect for people by interacting with the public with fairness and integrity (Treasury Board Secretariat, 2011). Transparency promotes engagement and accountability within the public sector. Transparency is not only critical in government hiring for accountability reasons, but also for recruitment reasons. In instances of perceived procedural unfairness or concealment, individuals are more likely to avoid or decline job positions (Suen, 2018).

Excellence

Excellence is highlighted as a core value in the federal Values and Ethics Code (Treasury Board Secretariat, 2011). The Code defines excellence as fair, timely, efficient and effective service with a commitment to continual innovation and improvement (2011, p.6). The Code states that "excellence in the design and delivery of public sector policy, programs and services is beneficial to every aspect of Canadian public life" $(2011$, p.4). It is critical to acquire excellent staff to maintain an excellent public service. High-quality labour is generally considered the lifeblood of any organization (Jobvite, 2016, p.1). Welldesigned hiring processes are key to acquiring excellent employees. The PSC reaffirms this statement, stating that an "effective staffing system is the backbone of a modern, well-functioning professional public service" (2011, s4.4).

\section{Potential Risks}

Unregulated SM screening is vulnerable to many issues that are in conflict with public- 
sector values. Although the practice is undoubtedly popular, the reliability and validity of SM screening are currently unknown (Landers and Schmidt, 2016). Potential issues surrounding reliability and validity compromise the employer's ability to make hiring decisions based on an accurate assessment of the candidate's fitness for the job in a fair and unbiased manner. Therefore, SM screening can conflict with merit-based hiring. One major issue is that any SM user (or the applicant themselves) can easily manipulate the reliability of their online presence by generating false or misleading content that skews the assessment of their job suitability. Misrepresentation can occur either deliberately or inadvertently through impressions management (Frantz, et. al., 2016). It is generally accepted in cyberpsychology that SM users often invest effort in curating positive online identities (Roulin and Levashina, 2016). Similarly, outdated information can contribute to a flawed representation of a candidate. As University of Texas SM professor Janet Johnson states, "data doesn't die" (CBSDFW, Nov. 2016). While the data may still be retrievable by employers, content on a candidate's pre-teen Myspace account is not likely to be reflective of the candidate's qualifications and personality a decade later.

From another facet, SM can magnify existing biases in the hiring process. As previously stated, private-sector employers reconsider hiring decisions based on SM content as innocuous as unprofessional screen names, grammatical errors, or alcohol consumption (Salm, 2017). SM contains personal information including, but not limited to, the applicant's gender, sexuality, ethnicity, religion and political affiliation. While this information may not be recorded in the formal decision-making, it is human psychology to be unconsciously influenced by the personal traits of individuals. Commonly known as the halo effect, hiring managers' assessment of a person's qualifications is influenced by whether they "like" the applicant, which is purely subjective and prone to bias (Simons, 1995; Nisbett and Wilson, 1977). The halo effect can lead candidates who were not the best fit for the job to be successful in a competition. Moreover, it can lead to the unfair exclusion of vulnerable groups like women, visible minorities, Indigenous peoples and members of the LGBTQ+ community (Ruggs, et, al. 2016). In this way, hiring bias in SM screening not only challenges merit-based procedures, but it also presents legal and ethical precariousness. The lack of transparency and openness around SM in the government only further exaggerates these issues. Cloaked SM screening creates a perception of unfairness that deters talent and contributes to a lack of trust in the public service (Suen, 2018). These are the theoretical conflicts between the merit principle and SM screening, but there is a need to be open about SM screening and pursue further research to assess the actual risk of unreliability, invalidity, and bias. 


\section{Potential Utility}

SM screening has potential to further the PSC's objective as it can facilitate best-fit hiring processes, strengthen the public service, uphold the value of excellence, and promote the stewardship of public dollars. The widespread use of SM screening throughout the private sector is one indicator of its utility. SM is a cost-effective and time-efficient source of background information (Clark and Roberts, 2010; Evuleocha and Ugbah 2018). 94\% of online Canadian adults contribute to an insurmountable amount of information (Gruzd et. al., 2018). SM screening can offer the same utility yielded in the private sector to the Government of Canada. The public sector often lags behind the private sector in terms of emerging trends and technology. However, competition between organizations to acquire talent is fierce. To remain competitive, and to maintain excellence and a strong public service, the public sector must modernize. Adopting new technologies and adapting to the emerging future of hiring is in line with the PSC's mandates. The PSC constantly seeks ways to improve the efficiency and efficacy of staffing procedures (Public Service Commission, 2011, s.4). A large focus of improvement efforts is modernization and investments to respond to transformations in technology (Public Service Commission, 2011, s.4.13). The PSC has identified data collection, infrastructure, analysis and measurement in particular as a limited area in public staffing (Public Service Commission, 2011, s.4.37).
SM screening can not only help the government remain competitive, modern, and cost-effective, but it can also support excellent, well-informed hiring decisions, which in turn supports stewardship. Screening is extremely important in government in order to: best match individuals' qualifications and experience to organizational needs; enrich the quality and efficacy of service; and reduce risk and liability for individuals and organizations (Public Safety Canada, 2012, p.7). Candidates can be assessed for their public service motivation though SM screening. Public service motivation refers to the alignment of individual values and government values and it has significant impacts on employee engagement, organizational health and productivity (Kernaghan, 2011). Making evidence-based hires is critical to maintain employee engagement (Kernaghan, 2011). Poorquality hiring decisions contribute to a substantial loss of public dollars (Public Service Commission, 2011, p.4.7). Absenteeism, presenteeism, incompetence, and fraud are examples of costly consequences that can result from poorquality hiring decisions. The average cost of a poor hiring decision is estimated at $30 \%$ of the employee's annual salary (Hampel, 2014). SM screening may provide a wealth of information that can mitigate the risk of an ill-suited hire. However, any potential benefit of SM screening must be considered against the risks. 


\section{Considerations and Recommendations}

The PSC makes it clear that any efforts for improvement within the public service must be pursued within the terms of the core values of merit, neutrality, fairness, access, transparency and representativeness (2011, s.4; 201l, s.3.2). Given the risks of unreliability, invalidity, bias, and legal and ethical issues discussed in the implications section, it is necessary to conduct further research before developing a federal SM screening policy. SM screening is novel and unique, causing many scholars to call for more research (Roth et al., 2016; Clark and Roberts, 2010; Landers and Schmidt, 2016). Requirements for future research include: (i) establishing a valid and reliable relationship between a candidate's SM content and their job suitability; (ii) examining hiring staff's ability to ethically and effectively assess SM content; and (iii) considering the legality of SM screening (Roth et al., 2016; Clark and Roberts, 2010; Landers and Schmidt, 2016). As the guardian of merit, transparency and excellence within public service staffing, it is recommended that the PSC lead this research within a publicsector context.

Regardless of the outcome of this research, this essay argues that SM policy should be established in the interest of transparency and merit. Public administration is largely "centered around procedural rules and regulations" (Peters and Pierre, 1998, p. 232). Based on my review, it appears that in its current state, SM screening is informal and discretional, which makes the hiring Social Media in Hiring process susceptible to legal and ethical risks and the violation of values. Hence, regulation is required to guide the process. That said, regulation and codification does not replace a capacity to practice ethical, value-based discretion. Regulation must be balanced with the instilment of commonly shared values (Caron and Giauque, 2006). Therefore, in addition to research-based regulation, it is recommended that the PSC develop and implement SM training that outlines how to professionally interact with SM and control SM-related bias. If future research indicates that the risks of SM screening outweigh the potential benefits, then there should be formalized prohibition of SM screening among government hiring managers in order to control and mitigate the risk of informal SM screening. Given the huge potential of SM screening, the importance of quality staffing, and the Government of Canada's commitment to excellence, it would be a disservice not to explore the possibility of standardizing SM screening across the public service.

\section{Conclusion}

Every appointment within the public service has significant ramifications for all other staff, the public service as an institution, and Canadian citizens (Public Service Commission, 2011, p.4.1). Therefore, publicsector hiring processes warrant innovative and well-researched policy. In this essay, I have advocated for the adoption of a federal SM screening policy to regulate what is likely a common, informal 
occurrence. This essay has reviewed the potential risks and benefits of SM screening within the context of public-sector values and an alarming lack of regulation. Based on this analysis and the existing body of research on SM screening, this essay joins other scholarship calling for further study, with the distinction of specific public-sector considerations. Future research must focus on establishing a reliable and valid link between SM and job fitness, the ability to ethically assess SM content, and the legality of doing so (Roth et al., 2016; Clark and Roberts, 2010; Landers and Schmidt 2016).

\section{References}

Bohnert, D., and Ross, H. R. (2010). The influence of social networking web sites on the evaluation of job candidates. Cyberpsychology, Behavior and Social Networking, 13: 341-347.

CareerBuilder (April 28, 2016). Number of Employers Using Social Media to Screen Candidates Has Increased 500 Percent over the Last Decade. Retrieved from https://www.careerbuilder.ca/share /aboutus/pressreleasesdetail.aspx? $\mathrm{sd}=4 \% 2 \mathrm{f} 28 \% 2 \mathrm{f} 2016 \% \mathrm{id}=\mathrm{pr} 945 \& \mathrm{e}$ $d=12 \% 2 f 31 \% 2 \mathrm{f} 2016$.

CareerBuilder (June 26, 2014). Number of Employers Passing on Applicants Due to Social Media Posts Continues to Rise, According to New CareerBuilder Survey. Retrieved from https://www.careerbuilder.ca/share /aboutus/pressreleasesdetail.aspx? $s d=6 \% 2 f 26 \% 2 \mathrm{f} 2014 \& \mathrm{id}=\mathrm{pr} 829 \& \mathrm{e}$ $d=12 \% 2 \mathrm{f} 31 \% 2 \mathrm{f} 2014$.

CBC News (Jan. 19, 2018). Don't Check Facebook before hiring, says privacy commissioner. Retrieved from http://www.cbc.ca/news/canada/n ewfoundland-labrador/socialmedia-hiring-public-bodies1.4492935 .

CBSDFW (Nov. 2, 2016). How Social Media Can Cost Someone Their Job. Retrieved from https://www.youtube.com/watch?v $=Z X 1 \mathrm{rHHp} 8 \mathrm{WDw}$.

Clark, L. and Roberts, S. (2010) Employer's Use of Social Networking Site: A Socially Irresponsible Practice. Journal of Business Ethics 95: 507525. DOI 10.1007/s10551-0100436-y

Comstock, C. (Jan, 24, 2011). Morgan Stanley Uses the "CiscoFatty" to teach its new hires how NOT to use Twitter and Facebook. Business Insider. Retrieved June 23, 2018 http://www.businessinsider.com/m organ-stanley-uses-the-ciscofattystory-to-teach-its-new-hires-howto-use-twitter-and-facebook2011-1.

De Forest Molina, A. (2009) "Values in Public Administration and the 
Role of Organizational Culture" in International Journal of Organization Theory and Behavior, 12(2), 266-279. Retrieved from https://searchproquestcom.ezproxy.library.dal.ca/docview /499126530?OpenUrIRefId=info:xri /sid:primo\&accountid=10406.

Government of Canada (2015). Best practices for unsupervised testing. Retrieved from https://www.canada.ca/en/publicservicecommission/services/publicservice-hiring-guides/bestpractices-unsupervisedtesting.html.

Government of Canada (2015). Structured reference check. Retrieved from https://www.canada.ca/en/publicservicecommission/services/publicservice-hiring-guides/structuredreference-checks.html.

Government of Canada (2018). Public service staffing. Retrieved from https://www.canada.ca/en/govern ment/publicservice/staffing.html.

Gruzd, A., Jacobson, J., Mai, P., and Dubois, E. (2018). The State of Social Media in Canada 2017. Version 1.0 Ryerson University Social Media Lab. DOI: 10.5683/SP/AL8Z6R
Hampel, E. (2014). A bad hire can cost $\$ 50,000$ - or more. Business Vancouver. Retrieved from https://biv.com/article/2014/07/abad-hire-can-cost-50000-or-more.

Jobvite (Feb. 17, 2015). Watch What you Post on Social Media. Retrieved from https://www.jobvite.com/employm ent-branding/jobvite-infographicwatch-post-social-media/.

Jobvite (2016). The Annual Social Recruiting Survey. Retrieved from https://www.jobvite.com/wpcontent/uploads/2016/09/Recruite rNation2016.pdf.

Kaplan, A. and Haenlein, M. (2010). Users of the world, unite! The challenges and opportunities of Social Media. Business Horizons 53: 59-68. doi:10.1016/j.bushor.2009.09.003.

Kernaghan, K. (2011). Getting engaged:

Public-service merit and motivation revisited. Canadian Public Administration, 54(1): 1-21.

Landers, R. and Schmidt, G. (2016) Social Media in Employee Selection and Recruitment: Theory, Practice, and Current Challenges. Springer.

Retrieved from https://ebookcentral-proquestcom.ezproxy.uleth.ca/lib/uleth/det ail.action?docID $=4519047$. 
Lindequist, E. (2006) "A Critical Moment: Capturing and conveying the evolution of the Canadian Public Service." Canada School of Public Service. Retrieved from http://publications.gc.ca/site/eng/ 290364/publication.html.

Messersmith, M. (Nov. 2016). Why Social Media Screening is So Important. Signet: Pre-employment Screening. Retrieved June 23, 2018 from http://www.signetscreening.com/w hy-social-media-screening-is-soimportant/.

Nisbett, R. E., \& Wilson, T. D. (1977). The halo effect: Evidence for unconscious alteration of judgments. Journal of Personality and Social Psychology, 35(4), 250256.

http://dx.doi.org/10.1037/00223514.35.4.250

Peters, G. and Pierre, J. (1998). Governance without government? Rethinking Public Administration. Journal of Public Administration Research and Theory 8(2): 223-243.

Popkin. H. (March, 27, 2009) Get the skinny on Twitter's "Cisco Fatty." NBC News. Retrieved June 23, 2018 from http://www.nbcnews.com/id/2990 1380/ns/technology_and_sciencetech_and_gadgets/t/getting- skinny-twitters-ciscofatty/\#.Wy5_uGYZMWo.

Public Service Commission of Canada (March 2011). Merit and nonpartisanship under the Public Service Employment Act (2003). Retrieved from http://publications.gc.ca/collection s/collection_2011/cfp-psc/SC3155-2011-eng.pdf.

Public Service Employment Act, Statues of Canada (2003, c.22). Retrieved from http://lawslois.justice.gc.ca/eng/acts/p33.01/.

Roulin, N. and Levashina, J. (2016) Impression Management and Social Media Profiles (pp. 223248). Landers, R. and Schmidt, G. (eds) Social Media in Employee Selection and Recruitment: Theory, Practice, and Current Challenges. Springer. Retrieved from https://ebookcentralproquestcom.ezproxy.uleth.ca/lib/uleth/det ail.action?docID $=4519047$

Ruggs, E., Walker, S., Blanchard, A., and Gur, S. (2016) Online Exclusion: Biases That may Arise when Using Social Media in Talent (pp. 289306). Landers, R. and Schmidt, G. (eds) Social Media in Employee Selection and Recruitment: Theory, Practice, and Current Challenges. Springer. Retrieved 
from https://ebookcentral-

proquest-

com.ezproxy.uleth.ca/lib/uleth/det

ail.action?docID $=4519047$.

Salm, L. (June 15, 2017). 70\% of employers are snooping candidates' social media profiles. CareerBuilder.

Retrieved from

Simons, T. (1995). Interviewing job applicants: How to get beyond first impressions. Cornell Hotel and Restaurant Administration Quarterly, 36(6), 21-27. Retrieved from Cornell University, School of Hospitality Administration site: http://scholarship.sha.cornell.edu/ articles/669/
Suen, Hung-Yue (2018). How passive job candidates respond to social networking screening. Computers in Human Behaviour 85(2018): 396-404. Retrieved from https://doi.org/10.1016/j.chb.2018. 04.018 .

Treasury Board Secretariat of Canada (2011). Values and Ethics Code for the Public Sector. Retrieved from https://www.tbs-sct.gc.ca/polcont/25049-eng.pdf. 